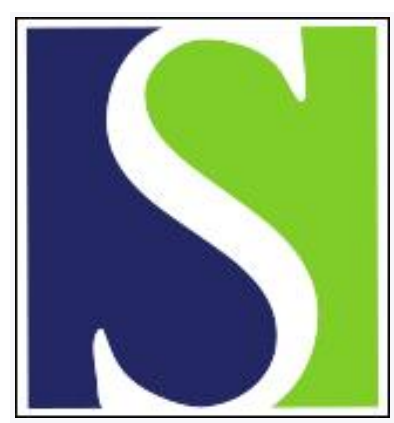

Scand J Work Environ Health 1995;21(1):68-69

https://doi.org/10.5271/sjweh.1370

Issue date: Feb 1995

Sex ratio of offspring of female physiotherapists exposed to low-level high-frequency electromagnetic radiation.

by James WH

This article in PubMed: www.ncbi.nlm.nih.gov/pubmed/7784868

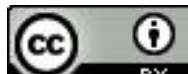




\section{Sex ratio of offspring of female physiotherapists exposed to low-level high-frequency electromagnetic radiation}

Larsen et al (1) reported that Danish physiotherapists exposed to low levels of electromagnetic radiation produce a highly significant, dose-related excess of daughters. The result needs replicating, but I would like to offer a provisional explanation.

I have gathered substantial quantities of data to support the hypothesis that the sex of mammalian (and among them, human) offspring is partially controlled by the hormone levels of both parents at the time of conception, high levels of gonadotrophin and progesterone being associated with the subsequent births of daughters and high levels of estrogen and testosterone with sons (2).

In mammals, the endocrine responses to acute microwave exposure are similar to the responses to nonspecific stressors such as heat (3). However this sort of response only occurs above a threshold. Below the threshold, exposure seems not to act as a stressor, For instance, rats exposed to low levels of radiation (with no increase in colonic temperature) showed inhibition of the normal circadian elevation of corticosterone (4). Various glucocorticoids suppress basal luteinizing hormone (LH) secretion $(5,6)$, and indeed a significant increase in LH has been reported in the pituitary of rats exposed to longterm low-level radiation (7). Therefore it seems that such exposure may also result in high gonadotrophin levels in women. If so, the phenomenon would explain the excess of daughters among physiotherapists exposed to low levels of electromagnetic radiation. To test this suggestion, it would certainly be worth assaying the hormone levels of female physiotherapists exposed to low levels of radiation.
Workers in occupational medicine might consider using the sex ratios (proportion of males) of offspring as a criterion of reproductive risk. Unusual sex ratios of offspring are characteristic of several diseases, for example, prostatic cancer (8), hepatitis (9), multiple sclerosis (10), otosclerosis (11), and non-Hodgkin's lymphoma (12). Moreover there is evidence that the reported low sex ratios for offspring of professional male divers (13, 14) and pesticide applicators (15) are caused by high levels of paternal gonadotrophin (16). Since high levels of gonadotrophin in men are associated with subfertility, there are grounds for concern over these occupations. However, an excess of daughters born to women is not equally suggestive of pathology. High levels of gonadotrophin in women are associated, for instance, with the births of dizygotic twins and may be a sign of well-being rather than otherwise. The idea that low-level microwave radiation may be beneficial should at least be considered.

\section{Acknowledgments}

I am grateful to Dr AI Larsen (Esbjerg, Denmark) for drawing my attention to his data and to Dr RD Saunders (National Radiological Protection Board) for forwarding me a copy of his monograph.

\section{References}

1. Larsen AI, Olsen J, Svane O. Gender-specific reproductive outcome and exposure to high-frequency electromagnetic radiation among physiotherapists. Scand J Work Environ Health 1991:17:324-9. 
2. James WH. The human sex ratio: part 2. a hypothesis and a program of research. Hum Biol 1987;59:873-900.

3. Saunders RD, Kowalczuk CI, Sienkiewicz ZJ. Biological effects of exposure to non-ionising electromagnetic fields and radiation: III. radiofrequency and microwave radiation. Chilton, Didcot, Oxon: National radiological Protection Board, 1991.

4. Lu S-T, Lebda N, Pettit S, Michaelson SM. Microwave-induced temperature, corticosterone, and thyrotropin interrelationships. J Appl Physiol Respir Environ Exercise Physiol 1981;50:399.

5. Baldwin DM. The effect of glucocorticoids on estrogen-dependent LH release in the ovariectomised rat and gonadotropin secretion in the intact female rat. Endocrinology 1979; 105:120-8.

6. Suter DE, Schwartz NB. Effects of glucocorticoids on secretion of LH and FSH by female rat pituitary cells in vitro. Endocrinology 1985;117:849-54.

7. Mikolajczyk H. Microwave-induced shifts of gonadotropic activity in anterior pituitary gland of rats. In: Johnson CC, Shore ML, editors. Biological effects of electromagnetic waves: selected papers of the USNC/URSI annual meeting, Boulder Colorado, October 1975; vol 1. Rockville, MD: United States Department of Health, Education and Welfare 1976:377. HEW publication (FDA) 77—8010.

8. James WH. The hypothesized hormonal control of human sex ratio at birth — an update. J Theor Biol 1990;143:555-64.

9. Chahnazarian A, Blumberg BS, London WT. Hepatitis B and the sex ratio at birth: a comparative analysis of four populations. J Biosoc Sci 1988;20:357_-_70.

10. James WH. Sex ratios of the offspring of patients with multiple sclerosis. Neuroepidemiology 1994;13:216-9.

11. James WH. Sex ratios in otosclerotic families. J Laryngol Otol 1989;103:1036—9.

12. Olsson $\mathrm{H}$, Brandt $\mathrm{L}$. Sex ratio in offspring with non-Hodgkin lymphoma. N Engl J Med 1982;306:367.

13. Lyster WR. Altered sex ratio in children of divers. Lancet $1982 ; 2: 152$.

14. Röckert HOE. Changes in the vascular bed of testes of rats exposed to air at six atmospheres absolute pressure. IRCS J Med Sci 1977; 5:107.

15. Potashnik G, Yanai-Inbar I. Dibromochloropropane (DBCP): an 8-year evaluation of testicular function and reproductive performance. Fertil Steril 1987;47:317-23.

16. James WH. Occupations associated with low offspring sex ratios. Am J Ind Med 1994;25:607-8.

William H James

The Galton Laboratory

University College London

Wolfson House

4 Stephenson Way

London NWI $2 H E$

United Kingdom 